\title{
Characterization of the Streptococcus pneumoniae NADH oxidase that is required for infection
} \author{
Martin Rosenberg ${ }^{1}$ and Damien McDevitt ${ }^{1}$ \\ Author for correspondence: Jun Yu. Tel: +1 5102916220 . Fax: +1510 2916196. \\ e-mail: jyu@xenogen.com
}

Jun $\mathrm{Yu}^{1}{ }^{1} \dagger$ Alexander P. Bryant, ${ }^{1}$ Andrea Marra, ${ }^{1} \ddagger$ Michael A. Lonetto, ${ }^{1}$ Karen A. Ingraham, ${ }^{1}$ Alison F. Chalker, ${ }^{1}$ David J. Holmes, ${ }^{1}$ David Holden, ${ }^{2}$

\footnotetext{
1 Anti-Infectives Research, SmithKline Beecham Pharmaceuticals Research and Development, 1250 S. Collegeville Road, Collegeville, PA 19426, USA

2 Department of Infectious Diseases, Imperial College School of Medicine, London W12 0NN, UK
}

Streptococcus pneumoniae is an important human pathogen capable of causing serious infections. NADH oxidase, a factor necessary for infection, was previously identified as part of a signature-tagged mutagenesis screen of a $S$. pneumoniae clinical isolate, 0100993. The mutant, with a plasmid insertion disrupting the nox gene, was attenuated for virulence in a murine respiratory tract infection model. A complete refined nox deletion mutant was generated by allelic-replacement mutagenesis and found to be attenuated for virulence $10^{5}$-fold in the murine respiratory tract infection model and at least $10^{4}$-fold in a Mongolian gerbil otitis media infection model, confirming the importance of the NADH oxidase for both types of $S$. pneumoniae infection. NADH oxidase converts $\mathrm{O}_{2}$ to $\mathrm{H}_{2} \mathrm{O}$. If $\mathrm{O}_{2}$ is not fully reduced, it can form superoxide anion $\left(\mathrm{O}_{2}^{-}\right)$ and hydrogen peroxide $\left(\mathrm{H}_{2} \mathrm{O}_{2}\right)$, both of which can be toxic to cells. Bacterial cell extracts from the allelic-replacement mutant were found to lack NADH oxidase activity and the mutant was unable to grow exponentially under conditions of vigorous aeration. In contrast, the mutant displayed normal growth characteristics under conditions of limited aeration. The $S$. pneumoniae nox gene was cloned and expressed in E. coli. The purified His-tagged NADH oxidase was shown to oxidize NADH with a $K_{m}$ of $32 \mu \mathrm{M}$, but was unable to oxidize NADPH. Oxidation of NADH was independent of exogenous FAD or FMN.

Keywords: nox gene, reactive oxygen species, virulence

\section{INTRODUCTION}

Streptococcus pneumoniae is an important cause of pneumonia, meningitis and bacteraemia, as well as of otitis media in young children. The pathogenic mechanisms have been extensively investigated (AlonsoDeVelasco et al., 1995; Bruyn et al., 1992; Paton et al., 1993). The polysaccharide capsule has been shown to be an important virulence factor for infection (Kelly et al., 1994; Watson \& Musher, 1990). In addition, several pneumococcal proteins, such as pneumolysin,

† Present address: Xenogen Corporation, 860 Atlantic Avenue, Alameda, CA 94501, USA.

$\ddagger$ Present address: Protein Design Labs, 34801 Campus Drive, Fremont, CA 94555, USA.

Abbreviation: STM, signature-tagged mutagenesis. autolysin and surface protein A, as well as some pneumococcal enzymes, such as neuraminidase, hyaluronidase, IgA1 protease and pyruvate oxidase, are also considered to play important roles in S. pneumoniae pathogenesis (Briles et al., 1998; Paton et al., 1993; Spellerberg et al., 1996).

S. pneumoniae is classified as a facultative anaerobe. Although it can grow in the presence or absence of oxygen, its energy metabolism is of an anaerobic type regardless of growth conditions (Konings \& Otto, 1983; Poolman, 1993). However, if molecular oxygen $\left(\mathrm{O}_{2}\right)$ is not fully reduced (four-electron reduction) to $\mathrm{H}_{2} \mathrm{O}$, it can undergo one- or two-electron reductions to form reactive superoxide anion $\left(\mathrm{O}_{2}^{-}\right)$and hydrogen peroxide $\left(\mathrm{H}_{2} \mathrm{O}_{2}\right)$, both of which are toxic to cells. The enzyme that converts $\mathrm{O}_{2}$ to $\mathrm{H}_{2} \mathrm{O}$ is an NADH oxidase called Nox. It has been identified and characterized from 
Streptococcus faecalis (Badway \& Karnovsky, 1980), Mycoplasma pneumoniae (Himmerlreich et al., 1996), Brachyspira hyodysenteriae (Stanton et al., 1999), Streptococcus pyogenes (Gibson et al., 2000) and Streptococcus mutans (Higuchi et al., 1993) and in S. pneumoniae it has been shown to be important for virulence in a murine model using an intraperitoneal challenge (Auzat et al., 1999). The enzyme was proposed to have a protective role in defence against $\mathrm{O}_{2}$ toxicity (Higuchi, 1992), or to function as an oxygen sensor (Auzat et al., 1999). In S. mutans, a minor $\mathrm{H}_{2} \mathrm{O}_{2}$-forming $\mathrm{NADH}$ oxidase called Nox1 has also been described (Higuchi et al., 1993).

In this study, we confirm the importance of NADH oxidase for S. pneumoniae virulence by showing significant attenuation for a nox allelic-replacement mutant in two additional $S$. pneumoniae models of infection. In addition, we have cloned, expressed and purified this important factor for virulence, confirmed its NADH oxidase activity and performed preliminary biochemical characterization of the enzyme.

\section{METHODS}

Bacterial strains and growth conditions. S. pneumoniae human clinical isolate 0100993 (serotype 3) was used as the parent strain for the construction of a nox allelic-replacement mutant. S. pneumoniae strain R6 is a single-colony isolate of strain R36A obtained from Avery's strain D39 (Avery et al., 1944; Ottolenghi \& Hotchkiss, 1962). S. pneumoniae strains were grown at $37^{\circ} \mathrm{C}$ with $5 \% \mathrm{CO}_{2}$ in Todd-Hewitt broth with $0.5 \%$ yeast extract or on tryptic soy agar plates containing $5 \%$ sheep blood, supplemented with $1 \mu$ g erythromycin $\mathrm{ml}^{-1}$ when appropriate. To grow S. pneumoniae under different aeration conditions, $20 \mathrm{ml}$ culture in a $250 \mathrm{ml}$ flask was shaken at 200 r.p.m. (vigorous aeration) or kept static (limited aeration). The anaerobic environment $\left(\mathrm{H}_{2}+5 \%\right.$ $\mathrm{CO}_{2}$ ) was generated and maintained by the GasPak Plus anaerobic system (Becton Dickinson). Escherichia coli strain $\mathrm{DH} 10 \mathrm{~B}$ was used as the host for plasmid construction and strain BL21 (DE3) was used for expression of the recombinant protein.

Phylogenetic analysis. Sequences were aligned with CLUSTALX (Thompson et al., 1994) followed by minimal manual editing. All gapped segments were removed from the analysis, leaving 389 positions. The phylogenetic tree was calculated by PUZZLE 4.02 (Strimmer \& von Haeseler, 1996). Ten thousand quartet puzzling steps were performed with the BLossum 62 model and eight gamma-distributed substitution rate categories.

Construction of a nox allelic-replacement mutant. An allelicreplacement cassette comprising a 511 bp fragment of upstream nox sequence, a $1234 \mathrm{bp}$ fragment containing an ermAM gene encoding resistance to erythromycin and a 465 bp fragment of directly downstream nox sequence was generated by PCR. This $2 \cdot 2 \mathrm{~kb}$ cassette was purified and $500 \mathrm{ng}$ was used to transform competent $S$. pneumoniae strain R6. Cells $\left(1.0 \times 10^{6}\right)$ were incubated at $30^{\circ} \mathrm{C}$ for $30 \mathrm{~min}$ followed by a $37^{\circ} \mathrm{C}$ incubation for 90 min to allow expression of the erythromycin-resistance gene. Bacteria were plated in agar containing $1 \mu \mathrm{g}$ erythromycin $\mathrm{ml}^{-1}$. Following incubation at $37^{\circ} \mathrm{C}$ for $36 \mathrm{~h}$, any visible colonies were picked and grown overnight in Todd-Hewitt broth supplemented with $0.5 \%$ yeast extract. Chromosomal DNA from the allelic-replacement $S$. pneumoniae strain R6 mutant was isolated and used to transform S. pneumoniae strain 0100993. The transformation procedure was identical to that for $S$. pneumoniae strain R6 except that a competence-stimulating heptadecapeptide (Havarstein et al., 1995) was added at a concentration of $1 \mu \mathrm{g} \mathrm{ml}^{-1}$ in the initial transformation mix. Mutants were selected by their abilities to grow in agar containing $1 \mu \mathrm{g}$ erythromycin $\mathrm{ml}^{-1}$.

NADH oxidase assay. NADH oxidase activities of the crude $S$. pneumoniae extracts or purified His-tagged Nox protein were measured spectrophotometrically at $30^{\circ} \mathrm{C}$ using a SpectraMaxPlus (Molecular Devices). The reactions were performed in the wells of a 96-well microtitre plate. Each well was preloaded with $180 \mu \mathrm{l} 0 \cdot 17 \mathrm{mM} \mathrm{NADH}$ in $50 \mathrm{mM}$ potassium phosphate buffer $\mathrm{pH} 7 \cdot 4$. The reaction was initiated by adding $20 \mu \mathrm{l}$ crude extracts or purified enzyme to a final volume of $200 \mu \mathrm{l}$. One unit of NADH oxidase activity was defined as the amount of enzyme ( $\mathrm{mg}$ protein) that catalysed the oxidation of $1 \mu \mathrm{mol} \mathrm{NADH}$ to $\mathrm{NAD}^{+}$per min at $30^{\circ} \mathrm{C}$.

$\mathbf{H}_{2} \mathrm{O}_{2}$ production. The $\mathrm{H}_{2} \mathrm{O}_{2}$ production assay was based on the method of Pick \& Keisari (1980). The S. pneumoniae pellet was resuspended in $1 \mathrm{ml}$ freshly made $\mathrm{H}_{2} \mathrm{O}_{2}$ working solution ( $5 \mathrm{mM} \mathrm{K}_{2} \mathrm{HPO}_{4}, 1 \mathrm{mM} \mathrm{KH} \mathrm{PO}_{4}, 140 \mathrm{mM} \mathrm{NaCl}$ and $0.5 \mathrm{mM}$ glucose, $\mathrm{pH} 7 \cdot 4)$. Prior to the assay, phenol red and horseradish peroxidase were added to a final concentration of $0.46 \mathrm{mM}$ and $0.046 \mathrm{U} \mathrm{ml}^{-1}$ respectively. After incubation at $37^{\circ} \mathrm{C}$ for $30 \mathrm{~min}$ with shaking, $10 \mu \mathrm{l} 10 \mathrm{M} \mathrm{NaOH}$ was added to stop the reaction. The reaction mix was centrifuged and $200 \mu \mathrm{l}$ supernatant was transferred to the wells of a 96-well plate. Absorbance was measured at $610 \mathrm{~nm}$ using a SpectraMaxPlus. $\mathrm{H}_{2} \mathrm{O}_{2}$ production was described as nmol $\mathrm{H}_{2} \mathrm{O}_{2}$ produced per $\mathrm{mg}$ bacterial protein per $30 \mathrm{~min}$.

Murine respiratory tract infection model. Bacteria for infection were prepared by inoculation of tryptic soy agar plates containing $5 \%$ sheep blood from frozen stocks followed by overnight growth at $37^{\circ} \mathrm{C}$ in $5 \% \mathrm{CO}_{2}$. Bacteria were recovered from plates, resuspended in PBS and adjusted to $\mathrm{OD}_{600} 0.95$. Animals (male CBA/J mice, 14-16 g) were anaesthetized with isoflurane $(3 \%)$ and $50 \mu \mathrm{l}$ bacterial inoculum $\left(7 \cdot 0 \times 10^{7}\right.$ c.f.u. $)$ was administered by intranasal instillation using a Pipetman (Rainin Instruction Co.). The mice were allowed to recover and given food and water ad libitum. Animals were observed three times daily and those unlikely to survive the challenge (i.e. exhibiting cyanosis, hypothermia, staring coat, or being moribund) were killed by $\mathrm{CO}_{2}$ overdose. Surviving animals were killed at $6-48 \mathrm{~h}$ post-infection by $\mathrm{CO}_{2}$ overdose and their lungs were aseptically removed and then homogenized in $1 \mathrm{ml}$ of PBS. The viable bacteria were serially diluted in PBS, spread on tryptic soy agar plates containing $5 \%$ sheep blood and enumerated after incubation at $37{ }^{\circ} \mathrm{C}$ supplemented with $5 \%$ $\mathrm{CO}_{2}$ overnight.

Mongolian gerbil otitis media infection model. Male Mongolian gerbils (40-60 g) were anaesthetized with isoflurane $(3 \%)$ and the area around the left ear bulla was prepared by swabbing with ethanol. Forty microlitres $\left(1.0 \times 10^{5}\right.$ c.f.u.) of $S$. pneumoniae (isolate 0100993 or the isogenic nox mutant) was prepared as described previously and injected through the bone of the left bulla, and the animals were allowed to recover under observation. Food and water were provided ad libitum and the gerbils were killed $96 \mathrm{~h}$ post-inoculation by $\mathrm{CO}_{2}$ overdose. The tympanic membrane was then examined and middle-ear aspirates were obtained by injecting $250 \mu \mathrm{l}$ PBS into the middle ear cavity and withdrawing the fluid contained 
therein. Aspirates were then serially diluted and evaluated for viable bacteria.

Cloning, expression and purification of His-tagged NADH oxidase. The sequence of the nox gene and its flanking region was obtained from the SmithKline Beecham database and from GenBank (accession number AAC26485). The full-length nox coding region was amplified by $P f u$ DNA polymerase (Stratagene) from $S$. pneumoniae strain 0100993 chromosomal DNA with primers noxup $\left(5^{\prime}\right.$-AGG AAA TTC ATA TGA GTA AAA TCG TTG TA-3') and noxdown (5'-AGT CAT TTG TTG GAT CCT CAT CA-3'). The purified nox fragment was digested with $\mathrm{NdeI}$ and BamHI (these sites were included in the primers noxup and noxdown respectively). A $1547 \mathrm{bp}$ NdeI/Bam HI-digested nox fragment was ligated with the expression vector pET28a (Novagen) that was also digested with NdeI and BamHI. The ligated plasmid was electroporated into competent cells of E. coli ElectroMax DH10B. After the nox sequence was confirmed using appropriate primers, the resulting plasmid pET28nox was introduced into E. coli strain BL21 (DE3) for the expression of His-tagged Nox.

The pET28nox-bearing BL21 (DE3) was grown to $\mathrm{OD}_{600} 0 \cdot 4$ in Luria broth at $37^{\circ} \mathrm{C}$. Expression of His-tagged Nox was induced by addition of $1 \mathrm{mM}$ IPTG, and after $3 \mathrm{~h}$, the bacterial cells were collected by centrifugation. The pellet was resuspended in $10 \mathrm{ml} 1 \times$ binding buffer from the His-tagged protein purification kit (Novagen). The bacteria were disrupted on ice by sonication for $30 \mathrm{~s}$ at amplitude 10 with $30 \mathrm{~s}$ intervals for a total of $6 \mathrm{~min}$ using a Soniprep150 (Sanyo). The His-tagged Nox protein in the supernatant was purified using a $\mathrm{Ni}^{2+}$ column according to the manufacturer's instructions. The concentration of purified protein was determined with a BCA kit (Pierce), with bovine serum albumin as standard. The purity of protein was examined with $10 \%$ NuPAGE gel from Novex.

\section{RESULTS}

\section{Identification of the nox gene}

A S. pneumoniae strain 0100993 plasmid-insertion mutant with a disrupted nox gene was previously identified as attenuated for virulence in a murine respiratory tract infection model when tested in a pool of 96 uniquely tagged mutants in a STM study (G. Lau and others, unpublished data). When tested individually in this model, the plasmid-insertion mutant was found to be attenuated $10^{3 \cdot 5}$-fold compared with the parental strain 0100993. DNA sequencing of the excised plasmid from the chromosome of the mutant revealed that the plasmid had inserted between codon 255/366 of an ORF that had $95.5 \%$ identity to the Nox NADH oxidase of 459 amino acids. The full-length nox gene from strain 0100993 was subsequently cloned and sequenced. The Nox protein sequence was $98.7 \%$ identical to that of Nox NADH oxidase from $S$. pneumoniae strain 1015 (GenBank entry AAC26485), with six amino acid differences at D265G, G288D, I320N, N340I, Y345N and K459N.

Phylogenetic analysis of Nox protein sequences (Fig. 1) revealed that the NADH oxidase of $S$. pneumoniae 0100993 was closely related to the NADH oxidases from S. mutans, spirochaetes, mycoplasmas, Enterococcus

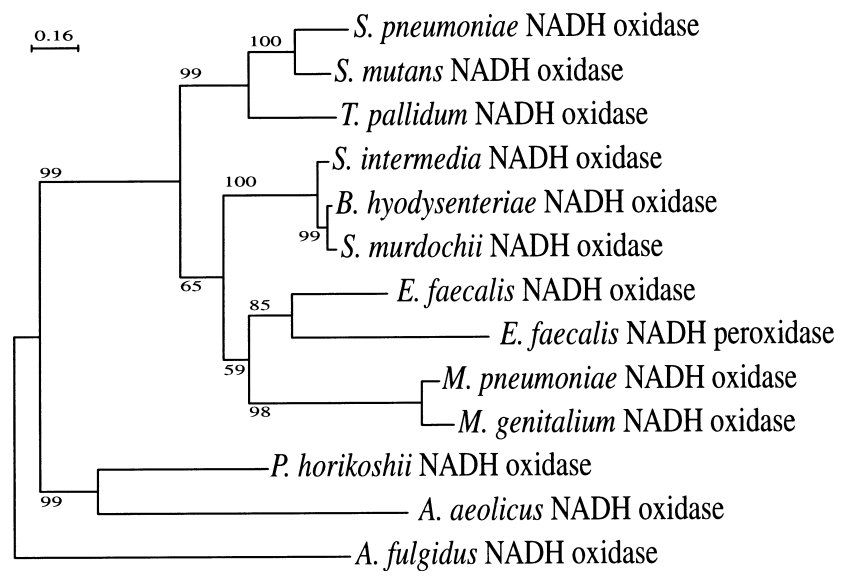

Fig. 1. Phylogenetic tree comparing the relativeness of Nox $\mathrm{NADH}$ oxidase protein sequences. Branch lengths are proportional to the amount of sequence divergence. Support values for internal branches are shown as percentages. The following sequences were included in the phylogenetic analysis, with GenBank (GB) or SWISS-PROT (SP) accessions: Streptococcus pneumoniae (this study), Streptococcus mutans (GB: D49951), Treponema pallidum (GB: AE001260), Serpulina intermedia (GB: AF060812), Brachyspira hyodysenteriae (GB: AF060802), Serpulina murdochii (GB: AF060813), Enterococcus faecalis (SP: P37061), Enterococcus faecalis NADH peroxidase (SP: P37062), Mycoplasma pneumoniae (SP: P75389), Mycoplasma genitalium (SP: Q49408), Pyrococcus horikoshii (GB: AP000006), Aquifex aeolicus (GB: AE000709), Archaeoglobus fulgidus NADH oxidase noxA-1 (GB: AE001088).

faecalis (both an NADH oxidase and an NADH peroxidase) and archaea. The Treponema pallidum and streptococcal sequences are more closely related to each other than to other members of their respective families, indicating possible convergence or lateral gene transfer. The redox-active cysteine of the Ent. faecalis NADH peroxidase (Ahmed \& Claiborne, 1989), which corresponds to Cys44 in S. pneumoniae $0100993 \mathrm{NADH}$ oxidase, is also conserved in all the NADH oxidase sequences analysed.

\section{Isolation of a S. pneumoniae nox allelic-replacement mutant}

The nox plasmid-insertion mutant identified from the STM study was not ideal for virulence studies, because of the possibility of residual activity being expressed by the relatively large truncated nox gene product (amino acid residues 1-366 intact). Moreover, insertional inactivation mutants often generate polarity effects on neighbouring genes. Hence, an allelic-replacement mutant was generated in strain 0100993 where the complete nox gene was deleted and replaced by ermAM, a selectable erythromycin-resistance determinant. This resistance gene lacked a downstream transcription terminator and was inserted so that transcription from its promoter was in the same direction as the nox gene in an attempt to minimize polar effects. There is a strong $\rho$-independent terminator $\left(\Delta G=-21.2 \mathrm{kcal} \mathrm{mol}^{-1}\right.$, $-88.7 \mathrm{~kJ} \mathrm{~mol}^{-1}$ ) (Tinoco et al., 1973) immediately 


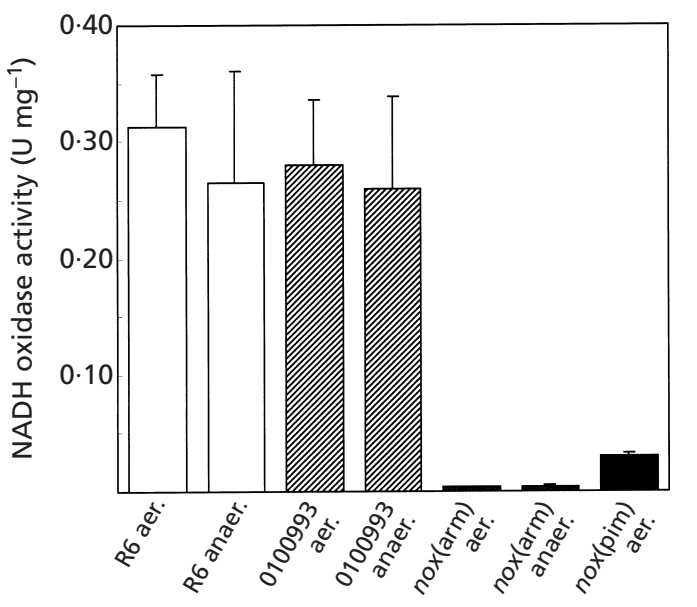

S. pneumoniae cell extracts

Fig. 2. NADH oxidase activities from cell extracts of strains 0100993, R6 and the nox mutants (arm: allelic-replacement mutant; pim: plasmid-insertion mutant). NADH oxidase activities of aerobically and anaerobically grown $S$. pneumoniae strains R6, 0100993 and the nox mutants were measured. One unit of NADH oxidase activity is defined as $1 \mu \mathrm{mol}$ NADH oxidized per min per mg bacterial extract. NADH oxidase levels are means of triplicate experiments \pm SD.

downstream of the nox gene, suggesting that nox is not co-transcribed with its nearest downstream ORF (152 bp downstream), which encodes a hypothetical protein. There is a $324 \mathrm{bp}$ gap between nox and its nearest upstream gene that is transcribed in the opposite direction to the nox gene. The chromosomal disruption of nox in the allelic-replacement mutant was confirmed by diagnostic PCR and Southern hybridization analysis (data not shown).

\section{NADH oxidase activity and $\mathrm{H}_{2} \mathrm{O}_{2}$ production by the nox allelic-replacement mutant}

To examine if the nox allelic-replacement mutant lacked NADH oxidase activity, crude cell extracts were prepared from aerobically or anaerobically grown cells of the allelic-replacement mutant, its pathogenic wild-type parent strain 0100993 and a non-pathogenic wild-type strain R6. As expected, the NADH oxidase activity was almost undetectable in cell extracts of the nox mutant compared to the activity in cell extracts of its parent strain regardless of the growth conditions (Fig. 2), demonstrating the effectiveness of the deletion replacement construct. The parental strain 0100993 and the strain R6 had significant NADH oxidase activities of $0 \cdot 28 \pm 0.06$ and $0 \cdot 31 \pm 0.05 \mathrm{U} \mathrm{mg}^{-1}$ respectively when grown in aerobic conditions (means $\pm \mathrm{SD}, n=3$ ). Interestingly, they had similar levels when grown anaerobically, suggesting that $\mathrm{NADH}$ oxidase activity is not inducible by $\mathrm{O}_{2}$ in $\mathrm{S}$. pneumoniae. The NADH oxidase activity of the STM-derived nox plasmid-insertion mutant was also determined (Fig. 2) to be $0.030 \pm$

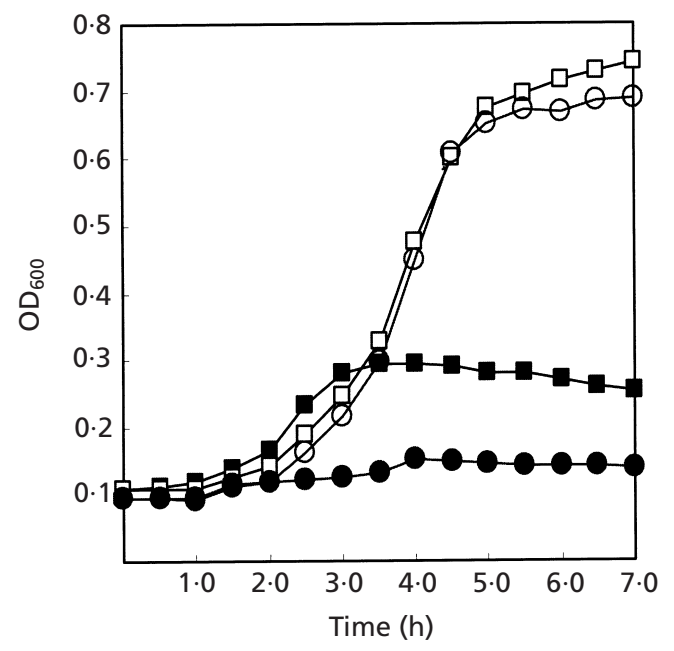

Fig. 3. Growth characteristics of strain 0100993 and the nox allelic-replacement mutant. $\mathrm{OD}_{600}$ readings were taken at 30 min intervals from cultures grown aerobically, after the strains were diluted from overnight seed cultures of aerobically grown 0100993 (squares) and the nox allelic-replacement mutant (circles). $\bigcirc, \square$, Limited aeration conditions (static);,

a, vigorous shaking (200 r.p.m.). The results from one of five experiments yielding similar results are shown.

$0.003 \mathrm{U} \mathrm{mg}^{-1}$, which represents $10 \%$ of the activity in the wild-type parent and significantly more activity than was found in the allelic-replacement mutant. This residual activity suggests that a truncated protein was being produced by the plasmid-insertion mutant.

Under aerobic conditions, $\mathrm{O}_{2}$ can be reduced to $\mathrm{H}_{2} \mathrm{O}$ by the Nox NADH oxidase, or it can be partially reduced to $\mathrm{O}_{2}^{-}$or $\mathrm{H}_{2} \mathrm{O}_{2}$. The possibility that the lack of NADH oxidase in the nox allelic-replacement mutant caused a change of $\mathrm{H}_{2} \mathrm{O}_{2}$ production was examined. $\mathrm{H}_{2} \mathrm{O}_{2}$ was produced at the rate of $22 \cdot 2 \pm 6 \cdot 7$ and $24 \cdot 1 \pm 5 \cdot 8 \mathrm{nmol}$ per 30 min per mg by the nox allelic-replacement mutant and the parent strain, respectively, indicating that there was no significant difference in $\mathrm{H}_{2} \mathrm{O}_{2}$ production by the mutant compared with the parent strain.

\section{In vitro growth characteristics of the nox allelic-replacement mutant}

As NADH oxidase is involved in the reduction of potentially toxic $\mathrm{O}_{2}$ to $\mathrm{H}_{2} \mathrm{O}$, we tested whether the nox allelic-replacement mutant was affected in its growth under different aeration conditions. In liquid culture under conditions of vigorous aeration (200 r.p.m.), growth of the allelic-replacement mutant was dramatically inhibited (Fig. 3) compared with that of the parent strain, suggesting that Nox NADH oxidase was required for growth of $S$. pneumoniae under these conditions. Under conditions of limited aeration, growth of the parent strain was much improved compared with growth under vigorous aeration. There was no significant difference in growth of the allelic-replacement 

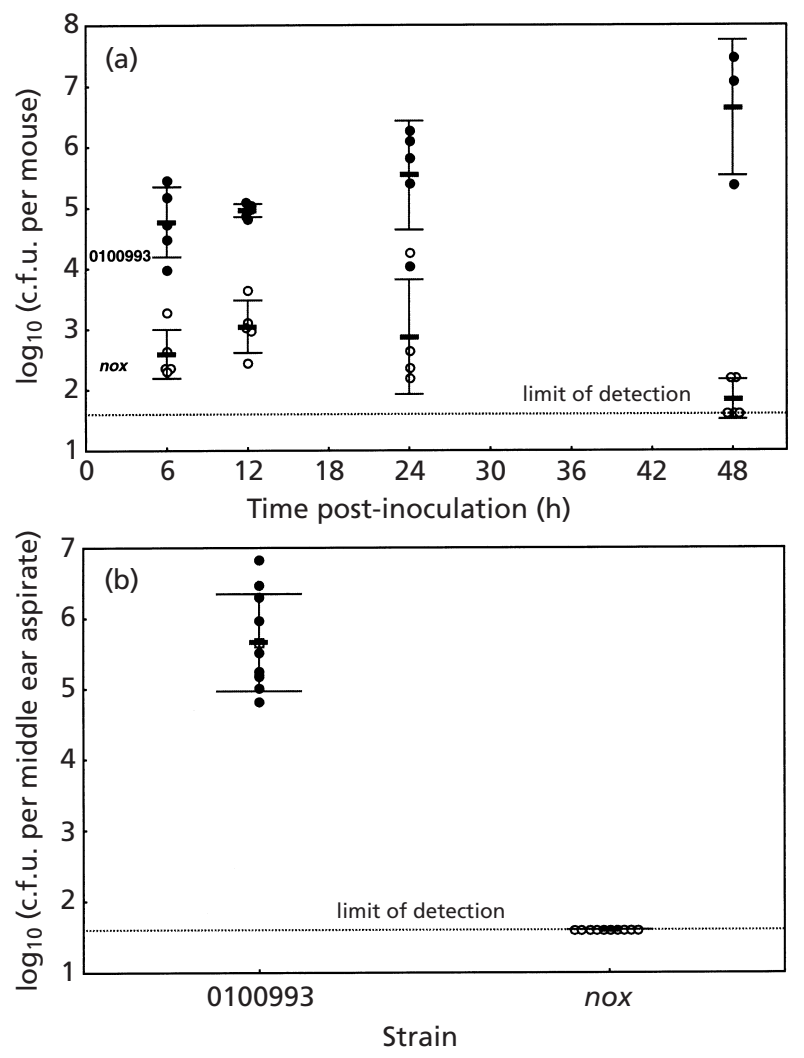

Fig. 4. Virulence testing of the nox allelic-replacement in animal models. (a) Murine respiratory tract infection model. For each time point $(6,12,24$ and 48 hours post-inoculation), five animals were infected intranasally with $7.0 \times 10^{7}$ c.f.u. per mouse of either the nox mutant $(O)$ or its parent strain 0100993 (b). (b) Mongolian gerbil otitis media infection model. For each group, ten animals were infected with $1.0 \times 10^{5}$ c.f.u. per gerbil of either the nox mutant $(O)$ or its parent strain 0100993 (). For details of the animal infection models see text.

mutant compared with that of the parent under limited aeration conditions.

\section{Virulence testing of the nox allelic-replacement mutant in animal infection models}

The requirement of the Nox NADH oxidase for $S$. pneumoniae infection was tested by comparing the virulence of the allelic-replacement nox mutant and its parent strain 0100993 in two different animal infection models. In the murine respiratory tract infection model, $7 \cdot 0 \times 10^{7}$ c.f.u. parent or mutant bacteria that had been grown in vitro under aerobic conditions, were administered intranasally into CBA/J mice. After $48 \mathrm{~h}$, a mean of $7 \cdot 0 \times 10^{6}$ c.f.u. per mouse was recovered from lungs infected with the parental wild-type strain (Fig. 4a). In contrast, only 80 c.f.u. per mouse was isolated from lungs infected with the nox mutant, representing a $10^{5}$ fold attenuation level. A time-course analysis revealed that the nox mutant was $10^{2}$ - to $10^{3}$-fold attenuated for virulence compared with the parent, even during the first $24 \mathrm{~h}$ of infection (Fig. 4a).

In a Mongolian gerbil otitis media infection model, two groups of ten animals were infected with $1 \cdot 0 \times 10^{5}$ c.f.u. of $S$. pneumoniae 0100993 or the nox allelic-replacement mutant. A mean of $7 \cdot 0 \times 10^{5}$ c.f.u. bacteria was recovered from middle ear aspirates of gerbils infected with the parent strain after $96 \mathrm{~h}$ of infection. In contrast, no bacteria were recovered (limit of detection) from the middle ear aspirates of any gerbils infected with the nox mutant (Fig. 4b). This suggested that the mutant was at least $10^{4}$-fold attenuated in this model of infection. This was the maximum level of virulence attenuation achievable with this model. Thus, the Nox NADH oxidase was required for $S$. pneumoniae virulence in two different models of infection.

\section{Isolation and characterization of the NADH oxidase}

The nox gene from S. pneumoniae 0100993 was cloned and expressed in E. coli as an N-terminally His-tagged fusion protein. The predicted molecular mass was 52355 $\mathrm{Da}$ and a strongly induced protein of approximately $53 \mathrm{kDa}$ was observed on an SDS-polyacrylamide gel (data not shown). Single passage of an induced bacterial lysate through a $\mathrm{Ni}^{2+}$ column yielded a $53 \mathrm{kDa}$ protein of greater than $95 \%$ purity as determined by SDSPAGE.

The purified His-tagged protein exhibited a specific NADH oxidase activity of $241 \cdot 3 \pm 2 \cdot 0 \mathrm{U} \mathrm{mg}^{-1}$ (mean \pm SD, $n=4)$, suggesting that this protein was indeed the Nox NADH oxidase. The oxidation of $\mathrm{NADH}$ was independent of exogenous FMN $\left(220 \cdot 2 \pm 27 \cdot 0 \mathrm{U} \mathrm{mg}^{-1}\right)$ or FAD $\left(239 \cdot 2 \pm 13 \cdot 1 \mathrm{U} \mathrm{mg}^{-1}\right)$. The $K_{\mathrm{m}}$ of the protein for $\mathrm{NADH}$ was $32 \mu \mathrm{M}$. As expected, NADPH was not oxidized by the NADH oxidase. The optimum $\mathrm{pH}$ for NADH oxidase activity was at $7 \cdot 0-7 \cdot 5$ in $50 \mathrm{mM}$ potassium phosphate buffer.

\section{DISCUSSION}

The Nox NADH oxidase may function as a housekeeping enzyme to reduce molecular oxygen to water, thereby avoiding the production of partially reduced reactive oxygen radicals, such as superoxide $\left(\mathrm{O}_{2}^{-}\right)$and hydrogen peroxide $\left(\mathrm{H}_{2} \mathrm{O}_{2}\right)$ both of which are toxic to cells. In the presence of metals such as iron or copper, $\mathrm{O}_{2}^{-}$and $\mathrm{H}_{2} \mathrm{O}_{2}$ can react with each other to form other active oxygen species, such as hydroxyl radicals $\left(\mathrm{OH}^{*}\right)$, which are highly reactive with DNA, membrane lipids and other essential cell components (Fridovich, 1978; Thomas \& Pera, 1983). Several reports have demonstrated that in the presence of copper or iron, the combination of $\mathrm{O}_{2}^{-}, \mathrm{H}_{2} \mathrm{O}_{2}$ and other oxygen radical species caused the inactivation of various cellular enzymes, including fructosyltransferase (Abbe et al., 1986), penicillinase (Samuni et al., 1981), acetylcholine esterase (Shinar et al., 1983), superoxide dismutase (Hodgson \& Fridovich, 1975) and glutamine synthetase 
(Oliver et al., 1984). Thus, a depletion of Nox NADH oxidase activity would be expected to impair the ability of bacteria to grow under oxygen rich conditions both in vitro and in vivo.

The requirement of the Nox NADH oxidase for $S$. pneumoniae infection was indicated by the isolation of a nox plasmid-insertion mutant in a STM virulence attenuation screen (G. Lau and others, unpublished data). When compared with its parent strain 0100993 , the $S$. pneumoniae mutant was $10^{3 \cdot 5}$-fold attenuated for virulence in a murine respiratory tract infection model. However, this plasmid-insertion mutant was capable of expressing a truncated protein of 366 amino acid residues ( $\sim 80 \%$ of the full-length protein of 459 amino acid residues) that contained the conserved cysteine at residue 44 that has been implicated in enzymic activity. The $11 \%$ residual NADH oxidase activity found in extracts of this mutant is likely to be due to activity from the truncated Nox produced by this mutant. Thus, a refined mutant was generated by allelic-replacement mutagenesis where the entire nox gene was deleted. This nox deletion mutant lacked any significant $\mathrm{NADH}$ oxidase activity. When tested in the same respiratory tract infection model, this allelic-replacement mutant was $10^{5}$-fold attenuated for virulence. The increase in the attenuation level between this mutant and the original plasmid-insertion mutant correlated with the elimination of residual NADH oxidase activity. The nox mutant was also at least $10^{4}$-fold attenuated for virulence in the Mongolian gerbil otitis media model, which is the maximum level of virulence attenuation achievable with this model. Thus, Nox is required for S. pneumoniae infection in both models tested, each of which deals with environments that are $\mathrm{O}_{2}$ rich (lungs and middle ear). Although we do not consider $\mathrm{NADH}$ oxidase as a classical virulence factor like an adhesin or a toxin, it is nevertheless required for infection in the models tested. These results are in agreement with those of Auzat et al. (1999), where NADH oxidase was also shown to be an oxygen sensor for S. pneumoniae infection. A murine intra-peritoneal challenge was used by Auzat et al. (1999), while our challenge was intranasal. It is unlikely that virulence attenuation is due to a polar effect of the allelic-replacement mutation on transcription of a downstream gene, as there appears to be a strong transcription terminator directly downstream of nox. We attempted to clone the S. pneumoniae nox locus in E. coli, for subsequent transfer to $S$. pneumoniae for complementation studies, but were repeatedly unsuccessful. Another group has also reported difficulty in cloning the S. pneumoniae nox locus in E. coli and suggested that upstream and/or downstream sequences might be toxic or unstable (Auzat et al., 1998).

Lack of NADH oxidase activity has been associated with oxygen-related in vitro growth inhibition in some S. mutans strains. When growing cells were shifted from anaerobic to vigorous aerobic growth conditions, the growth of oxygen-tolerant $S$. mutans strains was unaffected, but the growth of oxygen-sensitive strains was severely inhibited (Higuchi, 1984). Expression of the
Nox NADH oxidase was found to be induced by oxygen in oxygen-tolerant strains (i.e. from 0.052 to $0.985 \mathrm{U} \mathrm{mg}^{-1}$ ) but was not induced in oxygen-sensitive strains (i.e. from 0.050 to $0.059 \mathrm{U} \mathrm{mg}^{-1}$ ) (Higuchi, 1984) and was thus postulated to be important in protecting bacteria against oxygen-related toxicity (Higuchi, 1992). The growth characteristics of the $S$. pneumoniae strains used in this study (0100993 and R6) were similar to those of the oxygen-sensitive $S$. mutans strains described previously. Growth was significantly inhibited under conditions of vigorous aeration, probably because the low-level, non-inducible NADH oxidase $\left(0.26 \mathrm{U} \mathrm{mg}^{-1}\right.$ under anaerobic conditions and $0.28 \mathrm{U} \mathrm{mg}^{-1}$ under aerobic conditions) was not sufficient fully to protect bacteria against oxygen toxicity. The results from another laboratory also support our findings that $\mathrm{NADH}$ oxidase is required for $S$. pyogenes growth in oxygen-rich conditions (Gibson et al., 2000). The in vitro growth inhibition was almost complete when the gene for NADH oxidase was deleted in the nox allelicreplacement mutant. This nox mutant did grow normally in conditions of limited aeration, suggesting that other enzymes (e.g. pyruvate oxidase), were available to reduce oxygen during static growth (limited aeration) or that lower levels of $\mathrm{O}_{2}$ were not toxic. Apparently, the residual oxygen tolerance conferred by non-NADH oxidase enzymes is not sufficient to support growth of the $\mathrm{NADH}$ oxidase-deficient mutant either in vitro under vigorous aeration conditions or during infection.

Examination of public sequence databases revealed that Nox is present in S. pneumoniae, S. mutans, Ent. faecalis, mycoplasmas and spirochaetes and is broadly distributed in archaea. Interestingly, the Nox NADH oxidases appear to be related at the protein sequence level to the NADH peroxidase from Ent. faecalis strain $10 \mathrm{C} 1$, the X-ray crystal structure of which has been solved (Stehle et al., 1991). The proposed active redox centre and the putative FAD- and NADH-binding motifs of the Ent. faecalis NADH peroxidase (Ross \& Claiborne, 1992) are conserved in the various NADH oxidases, including S. pneumoniae Nox NADH oxidase, suggesting that these NADH oxidases might be functionally related. Auzat et al. (1999) mutated the catalytic Cys44 residue and the mutated protein, which was detected by Western blot from crude extracts, did not have measurable NADH oxidase activity.

The nox gene from S. pneumoniae 0100993 was cloned, expressed and purified as an $\mathrm{N}$-terminal His-tagged fusion protein. The enzymes from $S$. pneumoniae 0100993 (this study) and S. mutans (Higuchi et al., 1993) oxidized NADH, but not NADPH, at similar $K_{\mathrm{m}}$ values (32 and $25 \mu \mathrm{M}$ respectively). Their activities were independent of exogenously added FAD or FMN. In contrast, exogenous FAD was required for maximum activities of NADH oxidases of Ent. faecalis (Schmidt et al., 1986), Leuconostoc mesenteroides (Koike et al., 1985) and Mycoplasma caprocolum (Klomkes et al., 1985). Thus S. pneumoniae Nox NADH oxidase has biochemical characteristics similar to but distinct from other NADH oxidases. 
In summary, we have demonstrated that the $S$. pneumoniae Nox NADH oxidase is required for in vitro growth in oxygen-rich conditions and, importantly, for virulence in two distinct models of infection. For the allelic-replacement nox mutant, it is likely that loss of a protective function from NADH oxidase resulted in in vitro cell growth impairment and in vivo infection attenuation. The precise mechanism by which the Nox $\mathrm{NADH}$ oxidase is involved in the pathogenesis of $S$. pneumoniae remains to be explored.

\section{ACKNOWLEDGEMENTS}

This work was supported by a research grant from the Defense Advanced Research Projects Agency (DARPA) (N65236-97-1-5810). The content of this publication does not necessarily reflect the position or the policy of the US Government, and no official endorsement should be inferred.

We thank Drs G. Lau and S. Haataja for their contribution to the S. pneumoniae STM study which led to the identification of the nox plasmid-insertion mutant, and Drs R. D. Lunsford and $\mathrm{M}$. Burnham for their critical reading of the manuscript. We are grateful to members of our department for their suggestions and comments during this work.

\section{REFERENCES}

Abbe, K., Takahashi-Abbe, S., Schoen, R. A. \& Wittenberger, C. L. (1986). Role of NADH oxidase in the oxidative inactivation of Streptococcus salivarius fructosyltransferase. Infect Immun 54, 233-238.

Ahmed, S. A. \& Claiborne, A. (1989). The streptococcal flavoprotein NADH oxidase. I. Evidence linking NADH oxidase and NADH peroxidase cysteinyl redox centers. J Biol Chem 264, 19856-19863.

AlonsoDeVelasco, E., Verheul, A. F., Verhoef, J. \& Snippe, H. (1995). Streptococcus pneumoniae: virulence factors, pathogenesis, and vaccines. Microbiol Rev 59, 591-603.

Auzat, I., Le Bras, G., Le Thomas, I., Trombe, M.-C. \& Garel, J.-R. (1998). The NADH oxidase from Streptococcus pneumoniae. In ASM Conference on Streptococcal Genetics, Vichy, France, p. 68.

Auzat, I., Chapuy-Regaud, S., Le Bras, G., Dos Santos, D., Ogunniyi, A. D., Le Thomas, I., Garel, J. R., Paton, J. C. \& Trombe, M. C. (1999). The NADH oxidase of Streptococcus pneumoniae: its involvement in competence and virulence. Mol Microbiol 34, 1018-1028.

Avery, O. T., MacLeod, C. M. \& McCarty, M. (1944). Studies on the chemical nature of the substance inducing transformation of pneumococcal types. Induction of transformation by a desoxyribonucleic acid fraction isolated from Pneumococcus type III. $J$ Exp Med 79, 137-158.

Badway, J. A. \& Karnovsky, M. L. (1980). Active oxygen species and the function of phagocytes. Annu Rev Biochem 49, 695-726.

Briles, D. E., Tart, R. C., Swiatlo, E. \& 8 other authors (1998). Pneumococcal diversity: considerations for new vaccine strategies with emphasis on pneumococcal surface protein A (PspA). Clin Microbiol Rev 11, 645-657.

Bruyn, G. A., Zegers, B. J. \& van Furth, R. (1992). Mechanisms of host defense against infection with Streptococcus pneumoniae. Clin Infect Dis 14, 251-262.

Fridovich, I. (1978). The biology of oxygen radicals. Science 201, 875-880.
Gibson, C. M., Mallett, T. C., Claiborne, A. \& Caparon, M. G. (2000). Contribution of NADH oxidase to aerobic metabolism of Streptococcus pyogenes. J Bacteriol 182, 448-455.

Havarstein, L. S., Coomaraswamy, G. \& Morrison, D. A. (1995). An unmodified heptadecapeptide pheromone induces competence for genetic transformation in Streptococcus pneumoniae. Proc Natl Acad Sci U S A 92, 11140-11144.

Higuchi, M. (1984). The effect of oxygen on the growth and mannitol fermentation of Streptococcus mutans. J Gen Microbiol 130, 1819-1826.

Higuchi, M. (1992). Reduced nicotinamide adenine dinucleotide oxidase involvement in defense against oxygen toxicity of Streptococcus mutans. Oral Microbiol Immunol 7, 309-314.

Higuchi, M., Shimada, M., Yamamoto, Y., Hayashi, T., Koga, T. \& Kamio, Y. (1993). Identification of two distinct NADH oxidases corresponding to $\mathrm{H}_{2} \mathrm{O}_{2}$-forming oxidase and $\mathrm{H}_{2} \mathrm{O}$-forming oxidase induced in Streptococcus mutans. J Gen Microbiol 139, 2343-2351.

Himmerlreich, R., Hilbert, H., Plagens, H., Pirkl, E., Li, B. C. \& Herrmann, R. (1996). Complete sequence analysis of the genome of the bacterium Mycoplasma pneumoniae. Nucleic Acids Res 24, 4420-4449.

Hodgson, E. K. \& Fridovich, I. (1975). The interaction of bovine erythrocyte superoxide dismutase with hydrogen peroxide: inactivation of the enzyme. Biochemistry 14, 5294-5299.

Kelly, T., Dillard, J.P. \& Yother, J. (1994). Effect of genetic switching of capsular type on virulence of Streptococcus pneumoniae. Infect Immun 62, 1813-1819.

Klomkes, M., Altdorf, R. \& Ohlenbusch, H. D. (1985). Purification and properties of an FAD-containing NADH oxidase from Mycoplasma capricolum. Biol Chem Hoppe-Seyler 366, 963-969.

Koike, K., Kobayasi, T., Ito, S. \& Saitoh, M. (1985). Purification and characterization of NADH oxidase from a strain of Leuconostoc mesenteroides. J Biochem 97, 1279-1288.

Konings, W. N. \& Otto, R. (1983). Energy transduction and solute transport in streptococci. Antonie Leeuwenhoek 49, 247-257.

Oliver, C. N., Fulks, R., Levine, R. L., Fucci, L., Rivett, A. J., Roseman, J. E. \& Stadtman, E. R. (1984). Oxidative inactivation of key metabolic enzymes during aging. In Molecular Basis of Aging, pp. 235-263. Edited by A. K. Roy \& B. Chatterjee. New York: Academic Press.

Ottolenghi, E. \& Hotchkiss, R. D. (1962). Release of genetic transforming agent from pneumococcal cultures during growth and disintegration. J Exp Med 116, 491-519.

Paton, J. C., Andrew, P. W., Boulnois, G. J. \& Mitchell, T. J. (1993). Molecular analysis of the pathogenicity of Streptococcus pneumoniae: the role of pneumococcal proteins. Annu Rev Microbiol 47, 89-115.

Pick, E. \& Keisari, Y. (1980). A simple colorimetric method for the measurement of hydrogen peroxide produced by cells in culture. J Immunol Methods 38, 161-170.

Poolman, B. (1993). Energy transduction in lactic acid bacteria. FEMS Microbiol Rev 12, 125-148.

Ross, R. P. \& Claiborne, A. (1992). Molecular cloning and analysis of the gene encoding the NADH oxidase from Streptococcus faecalis 10C1. Comparison with $\mathrm{NADH}$ peroxidase and the flavoprotein disulfide reductases. J Mol Biol 227, 658-671.

Samuni, A., Chevion, M. \& Czapski, G. (1981). Unusual copperinduced sensitization of the biological damage due to superoxide radicals. J Biol Chem 258, 12632-12635.

Schmidt, H. L., Stocklein, W., Danzer, J., Kirch, P. \& Limbach, B. 
(1986). Isolation and properties of an $\mathrm{H}_{2} \mathrm{O}$-forming $\mathrm{NADH}$ oxidase from Streptococcus faecalis. Eur J Biochem 156, 149-155.

Shinar, E., Navok, T. \& Chevion, M. (1983). The analogous mechanisms of enzymatic inactivation induced by ascorbate and superoxide in the presence of copper. J Biol Chem 258, 1477814783.

Spellerberg, B., Cundell, D. R., Sandros, J., Pearce, B. J., IdanpaanHeikkila, I., Rosenow, C. \& Masure, H. R. (1996). Pyruvate oxidase, as a determinant of virulence in Streptococcus pneumoniae. Mol Microbiol 19, 803-813.

Stanton, T. B., Rosey, E. L., Kennedy, M. J., Jensen, N. S. \& Bosworth, B. T. (1999). Isolation, oxygen sensitivity, and virulence of NADH oxidase mutants of the anaerobic spirochete Brachyspira (Serpulina) hyodysenteriae, etiologic agent of swine dysentery. Appl Environ Microbiol 65, 5028-5034.

Stehle, T., Ahmed, S. A., Claiborne, A. \& Schulz, G. E. (1991). Structure of NADH peroxidase from Streptococcus faecalis 10C1 refined at 2.16 А resolution. J Mol Biol 221, 1325-1344.

Strimmer, K. \& von Haeseler, A. (1996). Quartet puzzling: a quartet maximum likelihood method for reconstructing tree topologies. Mol Biol Evol 13, 964-969.

Thomas, E. L. \& Pera, K. A. (1983). Oxygen metabolism of Streptococcus mutans: uptake of oxygen and release of superoxide and hydrogen peroxide. J Bacteriol 154, 1236-1244.

Thompson, J. D., Higgins, D. G. \& Gibson, T. J. (1994). CLUSTAL w : improving the sensitivity of progressive multiple sequence alignment through sequence weighting, position-specific gap penalties and weight matrix choice. Nucleic Acids Res 22, 4673-4680.

Tinoco, I., Jr, Borer, P. N., Dengler, B., Levin, M. D., Uhlenbeck, O. C., Crothers, D. M. \& Bralla, J. (1973). Improved estimation of secondary structure in ribonucleic acids. Nat New Biol 246, 40-41.

Watson, D. A. \& Musher, D. M. (1990). Interruption of capsule production in Streptococcus pneumoniae serotype 3 by insertion of transposon Tn916. Infect Immun 58, 3135-3138.

Received 7 August 2000; revised 19 October 2000; accepted 24 October 2000. 